\title{
ÇUVAŞ KÜLTÜRÜNDE ANT İÇME
}

\section{Cemalettín YavuZ}

Öz: Bu makalede Çuvaş kültüründe karşılaştığımız ant içme olgusu kavramsal, işlevsel, performatif ve anlamsal boyutlarıyla incelenmiştir. Makale iki ana bölüm meydana getirecek şekilde kurgulanmıştır. Birinci kısımda evrensel bir kültürel olgu olarak kabul edilen ant içmenin temel yapısal ilkeleri belirlenmiştir. Bu ilkeler; bir beyanda bulunma, bir veya birden fazla insanüstü otoritenin/garantörün gücüne ya da şahitliğine başvurma ve son olarak teminat ya da yaptırım işlevi gören şartlı öz kargışta bulunma şeklinde sıralanabilir. İnsanlığın ve kültürlerin evrensel özellikleri olarak görülen bu yapısal ilkeler temelinde Türk kültüründe ant içme geleneğiyle ilgili günümüze kadar yapılmış olan çalışmalardaki kavramlaştırma ve tasnif problemleri tespit edilmiştir. İkinci kısımda ise söz konusu yapısal ilkelerin, Çuvaş kültürünün kendine özgü özellikleriyle birleşmesi sonucu ortaya çıkan görünüşleri incelenmiştir. $\mathrm{Bu}$ görünüşler, her kültürü kendine özgü kılan dinamiklerin bir sonucu olarak kabul edilmiştir. Çevresel, sosyal, ekonomik ve tarihî etkenlerle şekillenen bu kültürel özelliklerin genetik boyutu göz ardı edilmemiş, Çuvaşlardaki ant içme biçimleri diğer Türk topluluklarındaki benzerleriyle de karşılaştırılmıştır. Verilerin elde edildiği dönemde Çuvaşların tarım ve hayvancılıkla geçinen, yerleşik, parçalı ve kapalı gruplardan meydana gelen bir topluluk olması ant içme biçimlerini de şekillendirmiştir. $\mathrm{Bu}$ nedenle Çuvaş antlarının büyük oranda anlaşmazlıkların giderilmesine dönük olduğu; toprağın, atalar kültünün ve doğal fenomenlerin en önemli otorite kaynakları olarak belirdiği görülmüştür.

Anahtar Kelimeler: Çuvaşlar, ant içmek, ritüel, otorite, öz kargış, Türk kültürü

\section{OAth-Taking In Chuvash Culture}

Abstract: In this study, the phenomenon of oath-taking in Chuvash culture is examined with its conceptual, functional, performative and semantic dimensions. The article is based on two sections. In the first one, the basic structural principles of the oath, which is accepted as a universal cultural phenomenon, are determined. These principles; making a statement, applying to the power or testimony of one or more superhuman authorities / guarantors, and finally making conditional self-curse, which acts as collateral or sanction. On the basis of these structural principles, which are seen as the universal characteristics of humanity and cultures, the conceptualization and classification problems in the studies related to the oath-taking custom in Turkic cultures have been determined. In the second part, the aspects of these structural principles, which emerged as a result of the combination of Chuvash culture with its

\footnotetext{
* Dr., Trakya Üniversitesi, Edebiyat Fakültesi, Türk Dili ve Edebiyatı Bölümü, EdirneTürkiye. / Hoca Ahmet Yesevi Uluslararası Türk-Kazak Üniversitesi, Türkoloji Enstitüsü, Türkistan-Kazakistan, yavuzcemalettin@gmail.com, ORCID: 0000-0001-6295-2179
}

(Yazının Geliş Tarihi/Received Date: 25.05.2021, Yazının Kabul Tarihi/Acceptance Date: 30.05.2021) 


\title{
U॰ Cemalettin Yavuz
}

\begin{abstract}
unique features, is examined. These aspects is recognized as a result of the dynamics that make each culture unique. The genetic dimension of these cultural characteristics, which are shaped by environmental, social, economic and historical factors haven't been ignored and the forms of oath-taking in the Chuvash have been compared with their counterparts in other Turkic communities. In the period when the given data were obtained, the fact that the Chuvash was a community of settled, fragmented and closed groups that lived on agriculture and animal husbandry also shaped the way they took the oath. Thus, as the Chuvash oaths are mostly used for settling disputes; also it has been observed that the earth, ancestral cult and natural phenomena appeared as the most important sources of authority.
\end{abstract}

Key Words: Chuvashes, oath taking, ritual, authority, self-curse, Turkic culture

\section{Giriş}

İnsana özgü evrensel bir olgu olarak karşımıza çıkan ant içme geleneği, Türk kültür çevrelerinde de geçmişten günümüze farklı biçim ve bağlamlarda yaygın olarak var olmuştur. Farklı Türk lehçe ve şivelerinde ant sözünün biçimleri, anlamı ve ant içme pratikleri çeşitli boyutlarıyla ele alınmıştır (İnan, 1998; Köse, 1991; Deniz, 1995; Durmuş, 2009; Durmuş, 2011; Aktaş, 2013; Ünal, 2013; Arvas, 2019). Bu çalışmada Çuvaş kültüründeki ant olgusu kavramsal, işlevsel, performatif ve anlamsal boyutlarıyla ele alınacaktır.

Çuvaş kültüründe ant olgusunu incelemeye başlamadan önce farklı Türk topluluklarındaki karşılıkları üzerine yapılan incelemelerdeki bazı noktalara temas etmek, bu çalışmada tercih edilen yöntemin ve yaklaşımın izahı açısından önemlidir. Çünkü söz konusu olguyu meydana getiren unsurlarla -söz, pratik, kutsal nesneler vs.- bütün olarak bu olgunun farklı boyutlarının -sosyal, dinî, psikolojik vs.- kavramsal ve yapısal bağlamda kategorileștirilmesi konusunda bazı karışıklıklar olduğu göze çarpmaktadır. Söz gelimi Abdülkadir İnan, ant (yani dostluk ve kardeşlik tesisi için yapılan tören) ve kargış (yani gerçek ile yalanı ayırt etmek için yapılan tören) (İnan, 1998: 330) arasında bir ayrım yaparak ilkini asli biçim, ikincisini ise eski Arap kültürüne dayanan bir unsur olarak değerlendirir.

Kargış, sözün yani andın bağlayıcılığını sağlayan bir unsur olarak ant olgusunun dişında ya da ona alternatif değil, aksine onun bir bileşeni olarak evrensel nitelik taşır. Nitekim 13. yüzyıl başlarında yazılmış bir Macar yıllığında aktarıldığına göre hükümdar seçilen Álmos'a önde gelen yedi alp bağlılığını kan akıtarak bildirir ve tarafların soyundan gelen birinin yemini ihlâl etmesi durumunda ebedî lanete uğramasını dilerler (Aktaş, 2013: 3). Bir ilişkinin tesisi ya da bir gerçeğin ya da yalanın ayırt edilmesi ile ilgili ayrım, ant olgusunun iç yapısına dönüktür ve bu konu ancak zaman (gelecek ya da geçmişe dönük olma) kriterine göre değerlendirilmelidir. Konuya böyle yaklaşıldığında bu iki tip andın özünde birbirinden farklı olmadığı ve birçok örnekte ikisinin de ritüel eylemlerle kuşatıldığı görülecektir. 
Daha sonraki çalışmalarda da "kargışa dayalı antlar" şeklindeki ayrımın devam ettirildiği görülmektedir. Buna ek olarak ant içme eylemine katılan ya da bundan etkilenen kişilerin sayısına göre bir sınıflandırma da yapılmıştır. Burada bir kişinin kendi kendine ant içmesi, kan kardeşi olmak isteyen iki kişinin ant içmesi ve boylar ya da milletlerin temsilcilerinin kendi halkları adına ant içmesi gibi üç farklı biçim varsayılmışıtır (Durmuş, 2011: 101). Bir kişinin kendi kendine "yalan söylemediğine/söylemeyeceğine" ya da "kötü alışkanlıkları bırakacağına" dair ant içmesi, şüphesiz ki onu bu eyleme sevk eden çevresel ve sosyal ilişkilerin bir sonucudur ve dolayısıyla bu anttan sadece kişinin kendisi etkilenmez. Aynı şekilde milleti adına uzlaşmaya dayalı olarak "anlaşmayı bozmayacağına" dair ant içen bir temsilci/yönetici, eylemlerinin sonucundan milleti kadar kendisi de etkilenecektir. Dolayısıyla bu ant tipleri arasinda da yapısal, işlevsel ya da anlamsal açıdan bir farklılık yoktur.

Benzer şekilde kargışa dayalı ant ile uzlaşmaya dayalı ant arasında da ayrım yapmak zordur. Söz gelimi Kazan Han'a asi olmayacağı konusunda, "Men Kazan'un nimetini çok yemişim, bilmezisem gözüme tursun! Kazagucda kazılık atına çok binmişem, bilmezisem mana tabut olsun... Men Kazan'dan dönmezem, bellü bilgil!" (Tezcan ve Boeschoten, 2012: 190) diyen Beyrek'in kargışa dayalı andı, Kazan Han'la hatta o günkü Oğuz toplumuyla aralarındaki geçmişten gelen ve tıpkı yöneticiler arasındaki ant gibi geleceğe işaret eden uzlaşıya işaret etmez mi?

Türk kültüründe ant olgusunun tasnifine dönük bir başka denemede "işlevsel açıdan" bir ayrım yapılarak "sözden ibaret ant içmeler" ve "söz ve hareketten oluşan komplike ant içmeler" şeklinde iki ana başlık ortaya konulmaktadır. Öncelikle, böyle bir tasnif ant olgusunun herhangi bir işlevine değil, yapısına ve birimlerine işaret etmektedir. Diğer taraftan hem ana başlık hem de alt başlıklardaki birçok birim arasında geçişkenliklerin son derece yüksek olduğunu gösterecek çok fazla örnek tespit etmek mümkündür. Tek bir örnek vermek gerekirse ilk başlık altında yer verilen "geleceğe dair vaatlerden oluşan antlar", "pazarlıklara dayalı antlar", "yapılan anlaşmalar temelinde antlar" gibi ant örneklerinin her biri geleceğe dönük uzlaşmalara işaret eder.

O hâlde ant olgusunu kuramsal bağlamda bir bütün olarak düşünmeli ama her bir vakayı (case) kendi bağlamında değerlendirmeliyiz. Bu bütünün elbette açık ya da örtük bileşenleri vardır. Richard Janko'nun "yemin etmek aslında yalan olması hâlinde- kişinin lanetlenmeyi dileyerek bir beyanın gerçekliğini onaylaması için kendinden daha büyük güçleri çağırmasıdı"” şeklindeki tanımına dayanan Sommerstein (2014: 1-2), ant içen kişinin şu üç şeyi aynı anda yaptığını yazar:

1. Ant içen bir beyanda bulunur. Bu, günümüz ya da geçmişle ilgili bir ifade olabilir; ikincisi olması durumunda ant doğrulayıcıdır ya da geleceğe dönük bir taahhüt olabilir ki bu durumda ant vaat edicidir. 


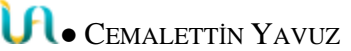

2. Ant içen kişi açık ya da örtük bir şekilde insanüstü bir gücü ya da güçleri, beyanın doruluğuna şahit ve gerçekliğinin garantörü olarak belirtir...

3. Ant içen kişi, iddianın yalan olması ya da vaadin ihlâl edilmesi hâlinde gerçekleşmesi için kendine dönük şartlı bir lanette bulunur, böylece kişi icabında garantör güç tarafından cezalandırılacaktır... Her durumda bu, andın tanımlayıcı anahtar özelliğidir; ant, güvenilirliği şartlı bir öz-lanetle güçlendirilmiş bir beyandır.

$\mathrm{Bu}$ bileşenlerle ritüel bir eylem meydana getiren andı kısaca beyan, otorite ve yaptırım sözleriyle formüle edebiliriz. Kan kardeşliği tesis etmek için içilen andın sözlü formülleri olmayabilir ya da kaynaklara yansımamış olabilir, ancak bu eylem açık bir şekilde ömür boyu sürecek bir bağın beyanı olmakla birlikte onun gereklilikleri ya da ihlâli durumunda karşılaşılması muhtemel durumlar taraflarca bilinmektedir. Kan, bu ilişkinin hem garantörü ve şahidi hem de vicdani ve toplumsal yaptırım gücünün simgesidir. Diğer bir ifadeyle ant, yazısız bir mukaveledir ve kargış ise ant içenin otoritenin eline en değerli şeyini -çoğunlukla canı, itibarı ya da en çok sevdiği şeyi- teminat olarak sunma biçimidir.

Abdülkadir İnan'ın ortaya koyduğu ayrım ise aslında iki ayrı müesseseye değil, andın zaman eksenindeki iki ayrı boyutuna işaret etmektedir. László Fosztó'nun (2008: 127) Romanya'daki Macar Çingeneleri arasında yaptığ 1 araştırmada ant içmenin iki boyutunu şu şekilde tablolaştırmıştır:

\section{Geçmişe dönük ant Geleceğe dönük ant}

\begin{tabular}{lll}
\hline Geçerlilik kriteri & Sözün gerçekliği & Söze bağlllık \\
Geçerlilik sınırı & Sınırsız & Düzenlenebilir/Uygulanabilir \\
Geçersizlik durumu & Yalan yemin & İhlal \\
Geri alma ihtimali & İmkânsız & Mümkün
\end{tabular}

Buna göre bir gerçeğin ortaya çıkarılması ve bir ilişkinin tesisi -her zaman ilişki tesis etmek zorunda değildir- için yapılan antlar arasındaki fark ilkinin geçmişe, ikincinin geleceğe ilişkin olmasındandır. Dolayısıyla temelde birisi "söz"ün gerçekliğine, diğeri "söz"e bağl1lığa vurgu yapar. Bu zamana dayalı farklılık doğal olarak andın öncesine ya da sonrasına dönük farklı boyutlarda çeşitli görünümlerin ortaya çıkmasını sağlar. Örneğin birisi kişiler arası sosyal bir çatışmayı çözmeye çalışırken diğeri başarılması hedeflenen bir işin ya da sosyal bir iliş̧kinin temelini oluşturur.

Evrensel niteliklerinin dışında andın bileşenleri olan beyan, otorite ya da bağlayıcılığın niteliği; bireyin ve toplumun sosyal, kültürel, dinî vs. dinamiklerine bağlı olarak değişiklik gösterecektir. 


\section{Çuvaşlarda Kültüründe Ant}

Çuvaş Türkçesinde "ant içmek" anlamında kullanılan ant tu-, antihh- ve intǐhsözü, diğer Türk lehçe ve şivelerindeki karşılıklarıyla aynı etimolojik köke dayanmaktadır. Bunun yanı sıra Arapça tevbe sözüne dayanan Çuvaşçadaki tupa'nın yardımc1 fiillerle meydana getirdiği tupa tu- (yemin etmek), tupa tıt(yemin etmek) (Aşmarin, 1929: 53; Aşmarin, 1937: 141; Yegorov, 1964:28, 258; Fedotov, 1996: 48-49, 248-249) ve sumah par- (söz vermek), ssír / tüpra şırt(toprak 1sırmak), şír / tĭpra kişla- (torpak kemirmek), tr̆pra şi- (toprak yemek) gibi birleşik ifadelerle Rusça kökenli priçak sözü de aynı anlama gelecek şekilde kullanılmıştır.

Çuvaş ant ritüellerinde en dikkat çekici unsurlardan birisi toprak/yerdir (ş̌ir). Etnografik verilerin yoğunlukla derlendiği 18. yüzyıl sonlarından 20. yüzyıl başlarına kadar olan süreçte yerleşik, tarıma dayalı bir yaşam süren, vatan anlamında yir-sub (yer-su) ifadesinin etimolojik açıdan bire bir dengi olan ş̌irşıv sözünü kullanan Çuvaşların Yer Ana (Şĭ Ama) diye niteledikleri yere yatıp toprağ 1 1sırarak ant içmeleri şaşırtıcı değildir. Diğer bütün ritüellerde de Tanrı ve diğer kutsallarla birlikte Yer Anası'na (Ş́ĭr Amiş̧i) dua edildiği görülmektedir.

Burada yer ile yerin altı, yani alt dünya arasında kavramsal bir ayrım yapmak gerekir. Yer, Çuvaş geleneksel inanışlarında "Erlik"in dünyası değil, insanların dünyasıdır. Üstündeki birçok bağlantı noktası ise -çukur, mezar, dere, mağara vd.- alt dünyaya açılan kapılardır. Bununla birlikte alt dünya, periyodik olarak yeryüzünü ziyaret eden/etmesi gereken ataların kendi düzenine göre yaşadıkları mekândır ve dolayısıyla kutsal kavramının dışında değil, onun bir parçasıdır. ${ }^{1}$ Dede Korkut'ta geçen yerin kertilmesi, "yer gibi kertileyim, toprak gibi savrulayım" ifadeleri ve farklı Türk boylarının destanlarında geçen benzer durumlarla (Gökdemir, 2003: 70; Arvas, 2019: 1006) Çuvaşlardaki yerle ilgili ant biçimi aynı değildir. Toprağın üzerine andı simgeleyen bir işaret çizmekle yerin/toprağın otoritesine başvurmak farklı şeylerdir. Bu ikinci biçimin Çuvaşlara özgü olduğu anlaşıllyor.

Hem geçmişe dönük hem de geleceğe dönük antlarda bu pratikle karşılaşmaktayız. Örneğin hayvanların zehirlenmesi, yangın, herhangi bir kutsala saygısızlık edilmesi gibi köyde gerçekleşen olumsuz bir durumda şüpheli görülen kişi toprağı 1sırmaya zorlanmakta, suçu sabit görülürse cezalandırılmakta ya da kınanmaktadır (Salmin, 2014: 94-95). Buna hırsızlık, dedikodu ya da toplumca onaylanmayan başka eylemleri de eklemek mümkündür. Çünkü yalan yere yemin eden kişi Tanrı'nın kutsal toprağına günahkâr bir dil ve ruhla yaklaştığında kesinlikle cezalandırılacaktır. Bir başka ifadeyle gerçekten masum olmayan kişi, kutsalla bu şekilde temas etmeye cesaret edemeyecektir. Bu tür antların genellikle topluluk ve ileri gelenlerin önünde gerçekleştirildiği görülüyor. Bu uygulamaların kendi bağlamı içerisinde toplumsal sorunların giderilmesine dönük, topluluğun kendi dinamiklerinden

${ }^{1}$ Bk. Yavuz 2019. 
referans alan bir yargılama biçimi olduğu açıktır. Merkezî otoritenin çevrede henüz yeterince yaygınlaşmamış olmasından öte, resmî kurum, norm ve yaptırımların topluluğun kendi değerleri karşısında yeterince itibarlı, güvenilir ve ulaşılabilir olmaması, endüstri öncesi toplulukların kendi içindeki çok parçalı ve içe dönük yapısının merkezî otoriteyle bütünleşmekten henüz uzak olması gibi etkenler göz önünde bulundurulduğunda Çuvaşlarda bu tür ritüellere ne derece yaygın olarak başvurulmuş olabileceğini tahmin etmek zor değildir.

$\mathrm{Bu}$ nedenle hem sözün gerçekliğinin hem de söze bağlılığın garanti edilmesinde kutsal ve temsilcileriyle fiziki ve manevi temas büyük bir öneme sahiptir. Öyle ki toprak, tarla ve orman gibi konularla ilgili çıkan problemlerin çözümünde bütün vücudu ya da sadece arkası çıplak bir şekilde toprağa yatılarak ya da oturularak ant içilmiştir. Yalan söyleyen kişinin bunu yapmaya cesaret edemeyeceği gibi cesaret edenlerin de hastalandığına dair inanış çok güçlüdür. Çünkü günahkâr olduğu hâlde ant içen kişiyi "kara toprak tutar" (hura şîir tıtat') düşüncesi hâkimdir (Stan'yal ve Rodionov, 2005: 34). Bu şekilde ant içen kişi gerektiği durumda tasarrufta bulunmak üzere canını simgesel olarak kutsala teslim etmiş olur. Toprakla fiziki temasın sınama aracı olarak güvenilirliğine başvurulması, söz konusu topluluk arasında bu düşüncenin yaygınlığına bağlıdır. Yine de bu riski alanların her zaman olabileceğinin de ortak bir kabul olduğu, birçok kişinin yalan yere yemin ettiği için hastalandığına inanılmasından anlaşılmaktadır. Kişinin ritüel sonrası yaşamında karşılaşacağı bütün talihsizlikler beyanının doğru olmamasıyla ilişkilendirilmektedir. İşte böyle bir ritüelde içilen ant şu şekildedir:

Doğru kalple yatıp toprağı dişliyorum. Tanrının toprağını temiz/kutsal olduğu için dişliyorum. Ruhum temiz olduğu için yakılmış mumu söndürüyorum. Birinin eşyasını aldıysam ömrümce Tanrı beni affetmesin, toprağı dişlediğim için beni yer yutsun, ölünce bedenimi toprak kabul etmesin. Doğru kalple Tanrı önünde yedi kez yakılmış mumu söndürüyorum (Stan'yal ve Rodionov, 2005: 34).

Başka bir ant söyleminde ise "Yüce Yer, Yer Anası! Bizim için ekilen, [üstünde] yürünen yerden kıymetlisi yok. Senin karşında suçluysam beni belalara gark et! Ben suç işlemedim. Bolluk ver, tahıl ver! Anne Yer için yere oturdum. Doğrusunu atalar bildirsin! (Stan'yal ve Rodionov, 2005: 34). Başka bir örnekte ise davalı kişi "Eğer senin eşyanı aldıysam yer beni yutsun!" diye ant içtikten sonra yere yatar, topraktan bir parça 1sırıp koparır ve bu toprağ davacı kişiye uzatır (Salmin, 2007: 318). Benzer bir uygulamada topraktan kesilen haç şeklindeki çimlerin votka bardağına konduğu ve davalı kişinin "Yalan söylüyorsam Tanrı canımı alsın!” diye ant içtiği görülüyor (Mészáros, 2000: 308). Böylece ant için kişi kutsal toprak aracıllğıyla kendi canını teminat olarak karşı tarafa sunmuş olur. Bu durumu kan kardeşliği ritüelleriyle ilişkilendirmek mümkündür. Aynı kapta kanlarını karıştırarak içen kişiler bir anlamda kendi canlarını da kan kardeşlerine teslim etmiş olurlar. Çuvaşlarda ise canın, kan yerine toprakla özdeşleştirilmesi söz konusudur. 
Burada aynı ant ritüelinin içinde bir mumum yedi kez söndürülmesi pratiğinin olduğunu da görüyoruz. Hristiyan inanışlarıyla birleştirilmiş olduğu görülen bu pratikte ant içen kişinin yaşamıyla ışığın yani güneşin ve mumun özdeşleştirilmiş olduğunu ifade etmek mümkündür. Böylece kişinin yaşamı riske atılarak andı test edilmiş olur. Başka bir kayda göre herhangi bir şey kaybolduğunda şüpheli kişi eve çağrılır, ikonların önünde mum yakıp üç kez söndürmesi istenir. Eğer kişi gerçekten suçluysa öleceğine inanılır (Salmin, 2014: 270).

Yerin kutsallı̆̆ına ve otoritesine başvurulan ve zamansal olarak geleceğe dönük olan başka ant içme örneklerine de rastllyoruz. Bu tür antlar sözün doğruluğuna değil, söze bağlılı̆ga ve birtakım sosyal müesseselerin kurulmasına ya da pekiştirilmesine işaret eder. Askere uğurlanan bir gencin toprak dişleyerek içtiği ant şöyledir:

Dedelerimizin ninelerimizin toprağı üstünde, köy kapısının önünde toprak dişleyerek ant içiyorum. Sizin ögütlerinizi hiçbir zaman unutmayacağım. Sağlıklı gidip diri dönebileyim. Bizim soyumuzda satılmış kimse yoktur, köyümüzde kaçak yoktur, akrabalarımızın arasında adsız asker yoktur. Ben bunu unutmuyorum. Siz de beni unutmayın. Kader değneğini yanımda götürüyorum, göğsüme koyup gidiyorum (Stan'yal ve Rodionov, 2005: 33).

Herhangi bir kargış ifadesi içermeyen bu ant ile yukarıda yer verdiğimiz Beyrek'in andı arasında ilkesel olarak hiçbir fark yoktur. Her ikisi de kendi sosyal çevresine ve bu çevrenin değerlerine olan bağlılığını koruyacağına, söz konusu sosyal ilişkiyi pekiştirerek sürdüreceğine teminat vermektedir.

Başkurt bölgesindeki Belebey'de Çuvaşlardan sadece baş kısmı derlenmiş Pitahir ile Yansihere adında bir destanda da padişah ve veziri dünür olmak isterler ve benzer bir şekilde ant içerler. Başkurt destanının Çuvaşlar arasındaki bu küçük yansımasında padişah ve veziri kıra çıkarlar, tavşan avlayarak doğacak çocuklarını evlendirmeye ant içerler ve toprağı kemirirler (Yumart ve Trofimov, 2014: 313). Böylece aralarındaki ilişkiyi başka bir boyuta taşıyarak sosyal bir müessese tesis etmiş olurlar.

Toprağın gücünden ve otoritesinden faydalanılarak gerçekleştirilen bu ant içme biçimi, folklor ürünlerinden faydalanılarak meydana getirilen telif eserlere de yansımıştır. 1996 yılında tam metni basılan ve Finlilerin Kalevala'sı gibi millî bir Çuvaş destanı yaratma çabalarının sonucu olarak Şuyın Hivetiri tarafindan düzenlenen Ulîp (Alp) adlı telif destanda da bu ant içme biçiminin örneklerini görüyoruz. Sinsilik, kurnazlık ve yalancılık özellikleriyle Çuvaşların destandaki en büyük düşmanlarından biri olarak karşımıza çıkan Supar (Bayram, 2012: 69), Ulĭp'ın babası Uslati'ye kendini affettirmek ve bağlılığını bildirmek için "bir kase toprak yiyerek" geleceğe dönük şöyle ant içer:

Ben hata yaparsam,

Çarpsın beni yıldırım. 
U๑ Cemalettin Yavuz

\author{
Sözümü tutmazsam, \\ Toprak yutsun orada. \\ Ant içiyorum önünde. \\ $\mathrm{Bu}$ andım çelikten, \\ Yüzylllarca geçerli (Bayram, 2013: \\ 46)
}

Aynı destanda yeni bir ülkeye göç etmeye hazırlanan Çuvaşların lideri Ulenke Han'ın buyruklarını yerine getireceğine dair, ileri gelen yöneticiler de bir kepçe toprak yiyerek "töreye göre" ant içerler (Bayram, 2013: 100). Böylece sosyal bir ilişkiyi ve bağl1lığ olarak sözün doğruluğunu ortaya çıkarmak ya da söze bağl1lı̆̆ temin etmek için bir araç olarak kullanılır.

Topraktan başka canla özdeşleştirilen ve bu bağlamda ant ritüellerinde otoritesine ve şahitliğine güvenilen başka bir araç ise kader sırı ̆̆ $/$ değneği (ş̌pa şalçi/patakí) denilen kabuğu soyulmuş ağaç dalıdır. Bu olgu İslam'daki amel defteri inanışını hatırlatmaktadır. Çuvaş inanışlarına göre herkesin bir kader değneği vardır ve kişinin ömrü boyunca yaptığı iyi ve kötü işler Tanrı'nın hizmetkârlarından olan Pülihsşi tarafindan bu değneğe yazılır. Bu değnek kiși öldüğünde mezarını ölçmek için kullanıldığı gibi ucuna bir kurdele bağlanılarak bayrak direği gibi kapının önüne de dikilir (Stan'yal ve Rodionov, 2005: 39). Ant içme törenlerinde sıkça kullanıldığı anlaşılan bu değneğin genellikle 1hlamur ağacindan (Mészáros, 2000: 308) olduğu aktarılıyor. Değneğe "puşı̆t ağacı" (puşît yıvış̧í) (Sboyev, 1856: 74) denmesinin sebebi de ihlamur ağacının ince ve uzun bir şekilde kıyılarak elde edilen parçalarından (puşît) sepet gibi eşyaların yapılıyor olmasıdır.

$\mathrm{Bu}$ değneğin üstünden atlayarak ant içme, en zorlu vakalarda başvurulan yöntemlerden biridir. Mezarlıkta değneğin üstünden atlayarak ant içen kişinin üstündeki bütün şüpheler kalkmaktadır (Salmin, 2007: 318). Değneğin üstünden atlayan kişi, "Değnek nasıl kuruduysa elim ve ayağım öyle kurusun!" diye ant içer (Mészáros, 2000: 308).

V. Magnitskiy böyle bir ritüeli detaylarıla aktarmaktadır. Köyde birinin hayvanları ya da başka bir şeyi çalındığında yetkili kurul -köyün ileri gelenleriçağrılır ve bütün halkın katıldığı bir ant töreni yapılması istenir. Mağdur kişi köyün dışında, kutsal ziyaret ve ibadet mekânı olan kiremette bir masa kurar. Masanın üstüne tuz, ekmek ve bıçak, altına bir kova su ve yere, masanın önüne değnek koyar. Bir parça ekmeği tuzlayıp bıçağın ucuna yerleştirdikten sonra ağzına götürür ve şu sözleri söyler: "Kim benim malımı çaldıysa kiremet onu görsün; kolsuz, bacaksız ve kör bıraksın, yiyeceksiz kalıp ölsün, fiziksel ihtiyaçlarını gideremesin.” Sonra kovadaki suyla yıkanır ve şöyle devam eder: "Yer, suyu yuttuğu gibi hırsızı da yutsun." Yerdeki değneğin üstünden atladıktan sonra "Bu dal gibi kurusun." der. Son olarak bütün köy halkı değneğin üstünden atlamak zorundadır ve kim tökezlerse hırsız odur. Çuvaşlar 
bu yemin hakkında şöyle derler: "Biz Rus değiliz, Çuvaşız. Rus gibi yemin etmek bizim için faydasızdır." (1881: 120-121).

Bir tür mahkeme olan bu ritüel gerçekten de Çuvaş dünyasını yansıtmaktadır. Öncelikle ritüelin kiremette yapılması, mekânın bütün kutsallığından faydalanmayı amaçlamaktadır. Masanın altındaki su, kaosun ve alt dünyanın; masa ve üstündekiler de orta ve yukarı dünyanın simgesidir. Yerdeki değnek ise şüphesiz ki yupa, kutsal dağ (Ama tu), kutsal ağaç (Ama yıvış) gibi farklı ölçeklerde yansımaları olan, evrenin katmanlarını bir arada tutan eksendir. $\mathrm{Bu}$ değneğin üstünden atlamak, dünyanın katmanları arasında bir çeşit yolculuk gibidir ve günahkâr olan bu süreci sorunsuz bir şekilde geçiremez. Suçlu buna cesaret edemez ya da sonrasında birçok hastalık ya da talihsizlik yaşar.

Çuvaşlardaki bu değnekle ant içme biçimine koşut uygulamaların farklı Türk topluluklarında da olduğu görülüyor. Kırgız-Kazaklar çoban değneği (kuruk) ve kamçı sap1 üzerinden atlayarak ant içmişlerdir (İnan, 1998: 322). Konya'da "yemin etmişler" yerine "değnekten atlamışlar" ifadesi kullanıldığını Cahit Öztelli aktarıyor. Buna "çöven atlama" da denmiştir. Yine Öztelli'nin Ali Rıza Yalgın'dan aktardığına göre Çepniler en büyük yeminlerini dedelerin elindeki kamış baston üzerinden atlayarak yapmışlardır. Başka aşiretlerde de anlaşmazlıklar, Pir Budak adı verilen ihtiyarlar tarafından değnek atlama yeminleri yaptırılarak gideriliyordu (Öztelli, 1959: 1939). Alevilikteki musahiplik töreninde de "erkân çubuğu" ve "tarik çubuğu" adı verilen kabuğu soyulmuş ve dağlanmış bir değnek kullanılır. Söz konusu törende bu değneğin oynadığı aktif rol (Ersal, 2011: 1087-1110), taliplerin dinî ve sosyal statülerindeki değişiklikler göz önünde bulundurulduğunda Çuvaşların kader değneği ile erkân çubuğunun aynı kozmik anlamı ve otoriteyi simgelediği düşünülebilir.

Kiremet gibi ant içmek için seçilen özel mekânlardan birisi de mezarlıktır. Mezarlıkta değnek tutularak yapılan bir ant içme töreninde şu sözler kaydedilmiştir: "Neslimizin başı Urtemi amcanın toprağının önünde, bütün köy ihtiyarlarının önünde söylüyorum. Bütün köy bilsin. Şimdi beni askere göndermeyin. $\mathrm{Bu}$ yıl ot biçme ayında [temmuz] evlenmem gerekiyor, ben sözümden dönemem. Bütün dünyanın karşısında söylüyorum, beni askere gönderirseniz üç kişinin canını alacaksınız" (Stan'yal ve Rodionov, 2005: 39). Soyun atası; kişinin kökeni, varlık sebebi ve onun üstündeki en güçlü otoritelerden birisidir. Bir başka ifadeyle ant içen kişi, geçmişini ve kökenini temsil eden ata mezarı ile bütün bir ömrünü temsil eden kader değneğini şahit göstererek, onların otoritesinden ve gücünden faydalanarak geleceğe dönük bir vaatte bulunmakta; köy meclisinin kendisiyle ilgili kararın etkilemeye çalışmaktadır.

Atalar kültünün bir yansıması olarak ölmüş ataların mezarı başında içilen andın en güçlü teminat olduğu anlaşılıyor. O. Vinogradov'un aktardığına göre bir gerçeğin ortaya çıkarılması gerektiğinde ileri gelenler bu ritüelin yapılmasını 
talep ederler. Böyle durumlarda kendisinden ant içmesi istenen kişinin bir akrabasının ya da köyde saygın birinin mezarına giderler. Şüpheli kişi elini mezarın üstünden ant isteyen kişiye uzatır ve aynı zamanda gerçeği söyleyeceğini beyan eder. Aksi takdirde mezarda yatan kişi onu öldürecek ya da cezalandıracaktır. Çuvaşlar bu şekilde ant içene tam olarak güvenirler, çünkü kimse yalan yere böyle ant içmeye cesaret edemez (Vinogradov, 1897: 3). Kişinin farklı şekillerde ettiği yeminlere inanılmadığında ataların huzurunda ant içmesi istenmiş ve bunu yapanın sözüne inanılmıştır (Stan'yal ve Rodionov, 2005: 38).

Ataların otoritesine başvurarak mezarın üstünden tokalaşma dışında farklı şekillerde de tokalaşarak ant içme biçimleri bulunmaktadır. Bunlar kendi çocuğunun üstünden, atın üstünden ya da boynu üstünden elini ant isteyen kişiye uzatarak yapılan ve aynı zamanda sözle yapılan ant içme biçimleridir. Yalnız burada mezar başında içilen anttan farklı olarak bir otoriteye/garantöre başvurmanın değil, bir teminat göstermenin söz konusu olduğunu belirtmek gerekir. Otorite ise başta Tanrı olmak üzere Çuvaşların diğer bütün kutsalları olarak kabul edilebilir. Burada kişi boynu üzerinden tokalaşarak kendi canını, çocuğu üzerinden tokalaşarak çocuğunun canını ya da atı üzerinden tokalaşarak atını feda etmektedir. Hem geleceğe hem de geçmişe dönük olarak içilen bu antlarda kullanılan bazı sözlü ifadeler şöyledir:

“İşte benim elim! Boynumun üstünden uzatıyorum! Doğruluk, geride kalmaz. Her zaman öne çıkar. Dünya doğruluktan yoksun değildir.”

"Bu eli iyilikle sıkarsanız biz ömür boyu dost olacağız. Yemin edelim!"

“At üstünden elimi uzatıyorum! Benim sözüm doğru!” (Stan’yal ve Rodionov, 2005: 38-39).

Ant içme olgusunun her zaman kişiler arasında olmadığını da ifade etmek gerekir. Herhangi birisi, bir hedefi başarma ya da gelecekte daha iyi bir duruma gelme amaciyla bireysel olarak da ant içebilmektedirler. Burada da yine bir beyan, ifade edilmiş ya da edilmemiş otorite/garantör ve şartlı bir şekilde feda edilen bir değer vardır. 1908 tarihli bir kayıtta, Yetirne uyezinin Kuşar Yuntapa köyünde bir köylünün çocuğunu eline alarak bir daha içki içmeyeceğine ant içtiği ve çocuğunun öleceğinden korktuğu için bir daha hiç içki içmediği (Salmin, 2014: 269) aktarılmaktadır.

Ekmek, tuz, tuzlu su ya da ekmek-tuz Çuvaş antlarında otoritesine başvurulan diğer unsurlar olarak karşımıza çıkmaktadır. G. F. Miller, Çuvaşların yumı̌s adı verilen ve falc1, büyücü ve hekimlik vasıfları taşıyan kişilerin idaresinde gerçekleşen bir ant ritüelini aktarmaktadır. Yumisş, üstüne tuz serptiği ekmeği bir bıçağın ucuna yerleştirerek suçlu olduğu düşünülen kişiye yedirmiş̧ir. Kişi bu şekilde ekmeği yedikten sonra sözlü olarak ant içmiştir (Stan'yal ve Rodionov, 2005: 37). "Tuz-ekmek hakk1" şeklinde Türk kültüründe tarihî ve coğrafi açıdan yaygın bir şekilde karşılaştı̆̆ımız bu durum açık bir şekilde yerleşik toplulukların hayati ihtiyaçlarına vurgu yapmaktadır. "Sözümü 
tutmazsam ekmeksiz tuzsuz yaşayayım!" ya da "Yalan söylüyorsam bu ekmektuzu bir daha görmeyeyim!” (Stan’yal ve Rodionov, 2005: 37) diye ant içen Çuvaşlar da ekmek ve tuzun kendileri için ne kadar hayati olduğunu ifade etmiş olurken aynı zamanda andı için canını ortaya koymuş olurlar.

Tanrı (Turī), güneş ve ay da Çuvaş antlarında otoritesine ve şahitliğine güvenilen diğer unsurlar olarak karşımıza çıkmaktadır. Örneğin güneşe bakılarak içilen ant, en güvenilir antlardan biri kabul edilmektedir. "Tupa ta Turişı̌n" [Tanrıya ant olsun] ifadesi, güneş ve ayla birlikte telaffuz edilebilirken bunun yanında değnek tutma, ekmek tuz yeme, kırda masa kurma gibi pratiklerin tümü aynı neden için yapılan bir ritüelde sırayla uygulanabilmektedir. Yahut herhangi bir ritüel olmadan bir iletişim ortamında da ant içilebilir. Bunlarla ilgili şu sözlü ifadeleri örnek gösterebiliriz:

"Yüce Güneş! Sana bakarak ant içiyorum. Beni, kötü bir iş yapmış olmakla suçluyorlar, şunları çalmış diyorlar. Ben çalmadım."

"Gerçekten mi? Ay-Güneş [de!]. Ay-Güneş, evet."

"Güneş var, güneş 1şı̆̆ı var... Yanlış bir şey yaptıysam benim olduğum yerde güneş doğmasın, günümü güneş aydınlatmasın!"

"Tanrıya ant olsun! Ekmek yemek [yemeye imkân verecek kadar] için güneş doğmasın. Güneşi görmeyeyim!”

“Tanrıya, güneşe, aya ant olsun!"

“Tanrıya ant olsun! Tanrı canımı alsın!” (Stan’yal ve Rodionov, 2005: 37).

\section{Sonuç}

Çuvaşların ant ritüelleriyle ilgili verilerde Tanrı (Turĭ), ölmüş atalar, mezar, toprak (yer), güneş, ay, tuz-ekmek, bıçak, kiremet, kader değneği gibi kutsal gücün farklı simgelerine başvurulduğu görülmektedir. Elimizdeki verilerde ant içmenin temeli olan beyanların ise çoğunlukla sözün gerçekliğine dair olduğu görülmektedir. Bu da tabii olarak Çuvaşların sosyokültürel durumu ve yaşayış biçimiyle ilgilidir. Çünkü eldeki veriler daha çok etnografik kaynaklara dayanmaktadır ve bu veriler elbette farklı Türk devlet ve topluluklarının tarihini, savaşlarını, destanlarını ihtiva eden kaynaklardan farklı olarak tarım ve hayvancılıkla geçinen yerleşik Çuvaşların gündelik hayatlarını tasvir etmektedir. $\mathrm{Bu}$ yaşam biçiminin şekillendirdiği dünya görüşünün destanlardaki gibi büyük ideallere matuf antlar ortaya koyması elbette beklenemez. Birçok Türk boyunda bir kapta kanlarını karıştırarak içmek ve böylece kan kardeşi olmaya ant içmek söz konusu iken Çuvaşlarda bunun yerine toprak yiyerek kendi halkına ve vatanına bağlılığını beyan etmek ya da 1 sırdığı toprağ doğruyu söylediğini temin etmek gibi uygulamaların olması bu şekilde açıklanabilir. Yine aynı nedenden ötürü kargış ifadelerinde ise ant içenin çoğunlukla kendi ya da aile üyelerinin (çocuk, eş, anne, baba) canını ya da 
sağlı̆̆ını, hayvanlarını, topraktan elde edeceği mahsulleri teminat olarak öne sürdüğü görülmektedir.

Kaynaklar neyin üzerine ant içileceğini, ant içmeye sebep olan olayın belirlediğine dair açık bir imada bulunmaktadır. Örneğin mal mülk ve vatan gibi konularla ilgili durumlarda ekmek yiyerek, araç gereçlerin kaybolması ya da bir tarlanın çiğnenmesi durumunda çocuk tutarak ya da askerlikle ilgili durumlarda kader değneğiyle ant içildiğine dair bilgi vermektedir. İfade etmek gerekir ki her ritiielde bir veya birden fazla kutsal unsura ve pratiğe başvurulabilmekte, anlaşmazlığın konusuna göre ritüel eylemin içeriği şekillendirilebilmektedir. Ancak hangi olay ya da durumda nasıl ant içileceği, hangi sözlerin söyleneceği sabittir demek mümkün değil. Çünkü bir ant içme ritüeli, bir kişi tarafından kendi başına uygulayabileceği ya da iki kişi arasında olabileceği gibi bütün bir topluluğun huzurunda yahut topluluğun tamamının katılımıyla gerçekleştirilebilmektedir. Andın arka planı ve insanları ant içmeye sevk eden olayın muhtevası, tarafların ikna olmasının zorluk derecesi gibi etkenler icranın gidişatını da belirleyecektir. Sadece "Ekmek-Tanrı" ifadesini söylemekten, özel bir mekânda birçok pratik ve kutsala başvurularak kalabalık bir katılımla gerçekleştirilen ritüele kadar performatif açıdan geniş bir yelpazede ant içme örnekleriyle karşılaşabiliyoruz ve bunların hepsinin temelde açık ya da örtük bir beyan, otorite/garantöre başvurma ve şartlı öz kargış içerdiğini görüyoruz.

\section{Kaynakça}

Aktaş, Erhan (2013). Türklerde ve Macarlarda Ant İçme ve Kan Kardeşliği. Acta Turcica, 2, s. $1-5$.

Arvas, Abdulselam (2019). Türk Destanlarında "Ant İçme" Ritüeli Üzerine Bazı Tespitler. Folklor/Edebiyat, 100, s. 997-1009.

Aşmarin, N. İ. (929). Ç̌̌vaş sümah ǐsem Kïneki/Slovar' Çuvaşskogo Yazıka. (Vıp. IV). Çeboksarı: Tipografiya Çuvaşskaya Kniga.

Aşmarin, N. İ. (1937). Ç̌vaşs šmah îsem Kïneki/Slovar' Çuvaşskogo Yazıka. (Vıp. XIV). Çeboksarı: Çuvaşskoye Gosudarstvennoye İzdatel'stvo.

Bayram, Bülent (2012). Şuyın Hivetiri'nin Ulıp Destanı (Çuvaş Kalevalası Üzerine Bir Inceleme). Ankara: Türk Kültürünü Araştırma Enstitüsü Yayınları.

Bayram, Bülent (2013). Ulıp-Çuvaş Destanı (Şuyın Hivetiri). Ankara: Türksoy.

Deniz, Özlem (1995). Manas ve Seytek Destanlarında Ant İçme Şekilleri. Bozkırdan Bă̆ımsızlığa Manas. (Hz. Emine Gürsoy Naskali). Ankara: TDK Yayınları, s. 256-268.

Durmuş, İlhami (2009). Türk Kültür Çevresinde Ant. Millî Folklor, 84, s. 97-106.

Durmuş, İlhami (2011). Türklerde Kan Kardeşliği ve Antla İlgili Unsurlar. Millî Folklor, 89, 100-108.

Ersal, Mehmet (2011). Alevi İnanç Sistemindeki Ritüelik Özel Terimler: Musahiplik. Turkish Studies, C. 6, 1, s. 1087-1110.

Fedotov, M. P. (1996). Etimologiçeskiy Slovar' Çuvaşskogo Yazıka. (Tom II). Çeboksarı: Çuvaşskiy Gosudarstvennıy İnstitut Gumanitarnıh Nauk. 
Fosztó, László (2008). Taking the Oath: Religious Aspects of the Moral Personhood among the Romungre. Romani/Gypsy Cultures in New Perspectives, s. 119-133.

Gökdemir, Gönül (2003). Türk Mitolojisinde Yemin-Ant Müessesesi. Millî Folklor, 59, s. 60-72.

İnan, Abdülkadir (1998). Makaleler ve Incelemeler. I. Cilt. Ankara: TTK Yayınları, s. 317-330.

Köse, Nerin (1991). Türk Halk Hikâyelerinde And. Türk Dili ve Edebiyatı Araştırmaları Dergisi, 6, s. 169-182.

Magnitskiy, V. K. (1881). Materialı k Ob'yasneniyu Staroy Çuvaşskoy Verı. Sobranı v Nikotorıh Mestnostyah Kazanskoy Gubernii. Kazan: Tipografiya İmperatorskago Universiteta.

Mészáros, Gyula (2000). Pamyatniki Staroy Çuvaşskoy Verı. (Çev. Yudit Dimitriyeva). Çeboksarı: ÇGİGN.

Öztelli, Cahit (1959). Türklerde And-Yemin. Türk Folklor Araştırmaları, 120, s. 19381940.

Salmin, A. K. (2007). Sistema Folk-religii Çuvaşey. Sankt-Peterburg: Nauka.

Salmin, A. K. (2014). Traditsionnaya Kul'tura Cuvaşey: Tekstı (Materialı Nauçnogo Arhiva Çuvaşskogo Gosudarstvennogo Instituta Gumanitarnı Nauk). Sankt-Peterburg: Filologiçeskiy Fakul'tet Pterburgskogo Gosudarstvennogo Universiteta.

Sboyev, V. A. (1856). İzsledovaniya ob İnorodtsah Kazanskoy Gubernii. Kazan: İzdaniye Knigoprodavtsa Dubrovina.

Sommerstein, A. H. (2014). What is an Oath? Oaths and Swearing in Ancient Greece. Berlin/Boston: De Gruyter, s. 1-5.

Stan’yal, V. P. - Rodionov, V. G. (2005). Pilsempe Kĭlĭsem. Şupaşkar: Ç̌̃vaş Kĭneke İzdatel'stvi.

Tezcan, Semih - Boeschoten, Hendrik (2012). Dede Korkut Oğuznameleri. İstanbul: Yap1 Kredi Yayınları.

Ünal, Orçun (2013). Ant Kelimesinin Kökeni Üzerine. Yemin Kitabı. (Ed. Emine Gürsoy Naskali). İstanbul: Kitabevi Yayınları, s. 225-233.

Vinogradov, F. (1897). Sledı Yazıçestva v Domaşnem Obihode Çuvaş. Simbirsk: Gubernskaya Tipografiya.

Yavuz, Cemalettin (2019). Çuvaș Mitleri ve Efsaneleri Üzerinde bir Inceleme. Trakya Üniversitesi Sosyal Bilimler Enstitüsü Yayımlanmamış Doktora Tezi.

Yegorov, V. G. (1964). Etimologiçeskiy Slovar' Çuvaşskogo Yazıka. Çeboksarı: Çuvaşskoe Knijnoe İzdatel'stvo.

Yumart, G. F.-Trofimov, İ. G. (2004). Ç̌̀vaş Halih Pultarulǐh ĭ. Halìh Epos ĭ. Şupaşkar: ÇKİ.

\section{ПРИНЕСЕНИЕ КЛЯТВЫ В ЧУВАШСКОЙ КУЛЬТУРЕ}

\section{АннотАЩия}




\section{U॰ Cemalettin Yavuz}

В данной статье исследуется принесение клятвы в чувашской культуре с концептуальной, функциональной, перформативной и семантической точки зрения. Статья состоит из двух основных разделов. В первом разделе определяются основные структурные принципы клятвы, которая считается универсальным культурным явлением. Эти принципы могут быть разделены в виде сделать заявление, применить силу или свидетельство одного или нескольких сверхчеловеческих авторитетов / гарантов и, наконец, сделать условное само проклятие, которое действует как залог или санкция. На основе этих структурных принципов, которые рассматриваются как универсальные характеристики человечества и культур, были определены проблемы концептуализации и классификации в современных исследованиях, связанных с традицией принесения клятвы в тюркской культуре. Во второй части рассматриваются аспекты этих структурных принципов, возникших в результате сочетания чувашской культуры с ее уникальными особенностями. Эти аспекты были признаны результатом динамики, которая делает каждую культуру уникальной. Генетический аспект этих культурных особенностей, которые формируются под влиянием экологических, социальных, экономических и исторических факторов, не был проигнорирован, и формы принесения клятв чувашей также были сопоставлены с их аналогами в других тюркских народах.

Из данных о клятвенных ритуалах чувашей можно заметить, что они прибегают к различным символам святой силы. Например, бог (Турі̌), умершие предки, могила, земля (почва), солнце, луна, соль-хлеб, керамит и жезл судьбы. Из имеющихся данных, кажется, что утверждение, которые являются основой клятвы, в основном касаются истинности слова. Это, конечно же, связано с социокультурным ситуацией и образом жизни чувашей. Поскольку имеющиеся данные в основном основаны на этнографических источниках, и эти данные отражают повседневную жизнь оседлых чувашей, которые занимались земледелием и животноводством, в отличие от источников, содержащих историю, войны, эпосы разных тюркских государств и общин. Конечно, нельзя ожидать, что мировоззрение, сформированное таким образом жизни, приведет к великим идеальным клятвам, как в эпосах. Именно поэтому чувашские клятвы в основном направлены на урегулирование спора. В то время как многие тюрки пьют кровь, смешанную в чаше, и, таким образом, клянутся быть кровными братьями, чуваши вместо этого едят землю, заявляя о своей преданности своему народу и Родине, а надкусив землю и передавая ее своему собеседнику, означает, что он говорит правду. Опять же, по той же причине видно, что человек, который дает клятву, в выражениях о проклятии в основном указывает на жизнь или здоровье членов своей семьи (детей, супругов, матери, отца), животных, урожай, который должен быть получен из почвы, в качестве залога.

В чувашских ритуалах клятвы можно ссылаться на один или несколько священных элементов и практик, а содержание ритуального действия может быть сформировано в зависимости от предмета спора. От простого произнесения фразы “Хлеб-Бог” до ритуала, выполняемого с участием 


\section{ÇUVAŞ KÜLTÜRÜNDE ANT İÇME • U}

большого количества людей в особенном месте с большим количеством практик и благословений, мы можем встретить широкий спектр примеров употребления клятв с перформативной точки зрения. И мы видим, что все они в основном связаны с явным или неявным заявлением, обращением к власти и проклятием, которое зависит от тех или иных условий.

Ключевые слова: чуваши, принесение клятвы, ритуал, власть, само проклятие, тюркская культура. 